\title{
PESSOA COM DEFICIÊNCIA: ESTIGMA E IDENTIDADE
}

\author{
Ana Paula Cunha dos Santos Fernandes (UEPA)* \\ Fatima Elisabeth Denari (UFSCar)**
}

\begin{abstract}
RESUMO
Neste artigo objetiva-se verificar, por meio das mídias audiovisuais, como as pessoas com deficiência são reconhecidas, porque, apesar dos direitos atuais adquiridos, ainda são visualizadas e/ou relatadas experiência negativas que abordam estigma, identidade e autonomia. Com isso, busca-se responder: Após décadas de educação inclusiva no Brasil, ainda existe preconceito ou estigma com a pessoa com deficiência? A metodologia é a netnografia, por ser uma pesquisa realizada em ambientes virtuais. Quanto à coleta dos dados, deu-se por meio da visualização e seleção de vídeos do YouTube que envolvem a temática estigma e identidade social. Para tanto, utilizou-se os descritores mais comuns como deficientes, deficiência visual, deficiência física, deficiência mental, deficiência intelectual, deficiência auditiva, pessoas com necessidades educacionais especiais, mongoloide, débil mental, ceguinho, surdo (piada) e surdinho. Como resultado, destacase a representação em mídia de forma ridicularizada, desrespeitosa, considerando a pessoa com deficiência como irresponsável, desatenta, fora do padrão social, não inteligente, agressiva, frívola, dentre outros.
\end{abstract}

Palavras-chave: Educação especial. Estigma. Identidade social. Diferença.

\begin{abstract}
PERSON WITH DISABILITIES: STIGMA AND SOCIAL IDENTITY

The aim of this paper is to check through the audiovisual media as people with disabilities are recognized. Thus we seek to answer, with a few decades of inclusive education in Brazil: there is still prejudice or stigma on the embodiment of those with disabilities? The methodology is netnography to be a survey conducted in virtual environments. The data collection will be through visualization and selection of YouTube videos that involves the theme stigma and social identity. In order to achieve this aim it has used descriptors such as: handicapped people, visual impaired people, physical impaired people, mental impaired people, intellectual impaired people, deaf person, people with special needs, "mongoloide", mentally retard, blind people, deaf (sick joke). As a result, we highlight: the representation in media is mocked, disrespectful, and consider those people as irresponsible, heedless, nonstandard, not wise, aggressive, frivolous, amongst others.
\end{abstract}

Keywords: Special education. Stigma. Social identity. Difference.

* Doutorado em Educação Especial pela Universidade Federal de São Carlos (UFSCar). Professora do Programa de Pós-Graduação em Educação na Universidade do Estado do Pará (UEPA). Coordenadora do Grupo de Estudos e Pesquisas em Educação Especial na Amazônia da Universidade do Estado do Pará (GEPEEAm/UEPA). E-mail: docenteapf@gmail.com

** Doutorado em Educação pela Universidade Federal de São Carlos (UFSCar).Professora do Programa de Pós-Graduação em Educação Especial na Universidade Federal de São Carlos (UFSCar). Pesquisadora no Núcleo de Estudos da Sexualidade (NUSEX/UNESP). E-mail: fadenari@terra.com.br 


\section{RESUMEN}

\section{PERSONAS CON DISCAPACIDAD: ESTIGMA Y IDENTIDAD SOCIAL}

El objetivo de este artículo es verificar, por medio de las medias audiovisuales, como las personas con discapacidad son reconocidas, pues, a pesar de los derechos actuales adquiridos, es aún visualizada y/o relatada a través de experiencias negativas que abordan estigma, identidad, autonomía. Así, buscamos contestar: ¿Después de algunas décadas de educación inclusiva en Brasil, todavía existe prejuicio o estigma sobre la persona con discapacidad? La metodología es netnografía, por ser una investigación realizada en ambientes virtuales. Los datos fueron recogidos a través de la visualización y selección de videos de Youtube sobre los temas estigma e identidad social. Para eso, se utilizaron descriptores comunes como discapacidad, discapacidad visual, discapacidad física, discapacidad mental, discapacidad intelectual, discapacidad auditiva, personas con necesidades especiales, "mongoloide", débil mental, cieguito, sordo (chiste), y "surdinho". El resultado obtenido es que la representación en la media es ridiculizada, irrespetuosa y considera la persona con discapacidad irresponsable, distraída, fuera de los estándares sociales, no inteligente, agresora, fútil, entre otros.

Palabras clave: Educación especial. Estigma. Identidad social. Diferencia.

\section{Introdução}

Em tempos de educação inclusiva, tem-se a ideia de que preconceito ou estigma são assuntos desnecessários e que todos já compreendem a condição da pessoa com deficiência reafirmada na Lei ${ }^{\circ} 13.146$ (BRASIL, 2015) e que agora já não a chamam de "doidinha", nem de portadora, nem de incapaz. Afinal, ela tem o direito garantido, em leis específicas, que a assegura nas escolas, tem descontos para compra de veículos, tem passe livre nos transportes terrestres em linha interestadual, tem descontos e "prioridade" no plano de habitação "Minha Casa, Minha Vida" e tem prioridade nos atendimentos em estabelecimentos diversos. Contudo, não é bem assim. A pessoa com deficiência, que é público-alvo da Educação Especial, ainda vivencia situações constrangedoras e excludentes, além de humilhantes, por todo tipo de indivíduo, independentemente do nível social ou de escolaridade.

O título deste trabalho surgiu a partir de uma ocorrência discriminatória entre uma pessoa com deficiência em formação na pós-graduação e uma pessoa que possuía o mais alto nível escolar. Esta última, após agredir, humilhar e constranger, perguntou à pessoa com deficiência se ela achava realmente que era capaz de estar naquele mesmo ambiente, de possuir alguma escolaridade. A pessoa com deficiência, assustada com o ocorrido, retrucou enfaticamente: "sou o quê?", depois dos inúmeros embates depreciativos. E a partir de então, associamos o ocorrido às mídias que são veiculadas em meios de ampla divulgação.

Assim, Magalhães (2010) descreve que é fundamental a clareza sobre a materialidade e a historicidade da identidade. Não se pode falar em constituição de identidade, mesmo pessoal, sem situá-la e contextualizá-la em um tempo e um espaço específicos, considerando as influências e pressões que o grupo social impõe a tal construção. Isso significa dizer que interações, interesses e relações de poder presentes na sociedade influenciam a forma de o sujeito constituir-se como pessoa no mundo.

Fernandes (2015) questiona: mas a identidade é formada por nós ou pelos outros? Somos o que queremos ser ou o que querem que sejamos? Este é um ponto delicado porque a identidade se constrói com o outro. E quem é este outro? É aquele que não te aceita e não permite que você seja "a ausência" de sua (pseudo) perfeição e superioridade?

Segundo Magalhães (2010), a convivência entre estigmatizados e normais favorece a construção de padrões de relação anteriormente inexistentes que, uma vez desenvolvidos, possibilitam formas de interação de grupos considerados diversos e/ou antagônicos. Contudo, a abordagem goffmaniana 
sustenta que a convivência não dirime totalmente o menosprezo e o preconceito das relações, pois continuam existindo previsões socialmente constituídas por meio das categorias nas quais somos todos "encaixados". Tais expectativas são sempre relembradas quando entramos em contato com alguém que vivencia o processo de estigmatização (GOFFMAN, 1980).

Goffman (1980) define estigma como um atributo considerado profundamente depreciativo pelo meio social, que conduz o indivíduo ao descrédito de forma intensa. $\mathrm{O}$ indivíduo estigmatizado é visto como defeituoso, fraco ou em situação de desvantagem em relação aos demais.

Ao descrever a situação "constrangedora" no cotidiano das pessoas com deficiência, alguns autores (GOFFMAN, 1980; MOREIRA, 2006; OMOTE, 2004; SCHILLING; MIYASHIRO, 2008) tentam descrever o que lhes ocorre, e embora relatem o fato, jamais terão a noção real do ocorrido e do prejuízo moral que acarreta. Ainda se vivencia a indiferença, o ignorar a existência, a subestimação tanto nas instituições de ensino como em ambiente profissional. Ao romper a situação constrangedora, a pessoa com deficiência consegue duas reais conquistas: a escolarização e a profissionalização. Porque não basta ser escolarizado, possuir um diploma de ensino superior, com mestrado e doutorado; é preciso passar pelos concursos da vida, em que pessoas com suas subjetivações, mesmo olhando seu currículo, vão deduzir, afirmar e reproduzir friamente que você não é capaz de se estabelecer naquele lugar, ou simplesmente alegar em suas considerações um motivo torpe com a única finalidade de exclusão, de propor a este a subestimação e a condição de inferioridade.

Portanto, será muito provável que pessoas com qualificações, inclusive com graduação, sejam vistas em balcões de estabelecimento comercial ou trabalhando como autônomos, por não conseguirem transpor a barreira para a profissionalização. Muitos já nos disseram: para que sair de casa se vou precisar brigar com o mundo? Outros dizem que devemos lutar sempre.

Não temos por intenção desestimular. Ao contrário, queremos que estejam preparados para o confronto com estes que se satisfazem pelo depreciar.
Na Cartilha do Censo 2010 - Pessoas com Deficiência (OLIVEIRA, 2012) é apresentado que, na população com deficiência, $14,2 \%$ possuíam o fundamental completo; $17,7 \%$, o médio completo; e 6,7\% possuíam superior completo. Mesmo com exigência legal de cotas para trabalhadores com deficiência, a participação deles no mercado de trabalho, em 2010, ainda era baixa quando comparada à das pessoas sem deficiência. Do total de 86,4 milhões de pessoas, de 10 anos ou mais, ocupadas, 20,4 milhões eram pessoas com deficiência, 23,6\% do total. Em 2010, havia 44.073.377 pessoas com pelo menos uma deficiência em idade ativa, mas 23,7 milhões não estavam ocupadas.

Amaral (1992) afirma: o fato é que - seja da ótica de quem a vive, seja da ótica de quem a vê-a deficiência, do ponto de vista psicológico, jamais passa em "brancas nuvens". Goffman (1980, p. 4) descreve que estigma refere-se à " [...] situação do indivíduo que está inabilitado para a aceitação social plena", e, consequentemente, promove uma generalização e a desumanização da pessoa com algum tipo de diferença significativa - uma deficiência. Historicamente, a deficiência está associada a uma situação de desvantagem. Refere-se à condição de uma situação de desequilíbrio, que só é possível num esquema comparativo: aquela pessoa, com alguma deficiência, em relação aos demais membros do seu grupo.

Consideramos, neste artigo, a terminologia pessoa com deficiência, baseados no Decreto $n^{\circ}$ 6.949 (BRASIL, 2009), que promulga a Convenção Internacional sobre os Direitos das Pessoas com Deficiência, realizada em Nova York, em 2007. Todavia, as nomenclaturas utilizadas nas mídias ou documentos serão mantidas para fins de análise e possível contraponto.

Para Amaral (1992, p. 9), a deficiência primária "[...] engloba o impedimento (dano ou anormalidade de estrutura ou função - o olho lesado, o braço amputado, a perna paralisada)". Esta se refere, efetivamente, à deficiência propriamente dita, à restrição, perda de atividade, sequela - o não enxergar, o não manipular, o não andar. Atualmente, segundo esta autora, reconhece-se que a deficiência secundária é a responsável principal no impedimento do desenvolvimento do indivíduo, pois o aprisiona na rede das significações sociais, com seu 
rol de consequências, como atitudes, preconceitos, estereótipos, o que acaba por legitimar a diferença e, consequentemente, a exclusão.

Na visão de Oliveira (2008), a educação inclusiva, ao propor uma educação para todos e uma educação para a diversidade, que respeite as diferenças, apresenta como referencial a diferença como alteridade, o outro como "distinto", superando a visão de diferença de caráter identitário e hegemônico estabelecida em relação a um outro, o "normal".

A educação inclusiva é entendida como a inclusão de crianças e jovens que apresentam necessidades educativas especiais em classes comuns do ensino regular, com o objetivo de se ter uma educação para todos, uma escola que acolha os diferentes e desenvolva uma prática escolar de convivência com a diversidade e as diferenças culturais e individuais (OLIVEIRA, 2008).

Aran (2002) nos diz que devemos estar muito atentos para que não estejamos contribuindo para manter ou provocar a desigualdade. Um enfoque que priorize a atenção à diversidade deve envolver toda a escola. Desvendar o mundo dos significados da diversidade ou da diferença e ver o que se quis fazer com elas é um caminho para descobrir práticas, tomar consciência e poder administrar os processos de mudança de uma maneira um pouco mais reflexiva.

A diversidade alude às circunstâncias dos sujeitos de serem diferentes (algo que, em uma sociedade tolerante, liberal e democrática, é digno de respeito). A diferença não é somente uma manifestação do ser único que cada um é; em muitos casos, é a manifestação de poder ou de chegar a ser, de ter possibilidades de ser e de participar dos bens sociais, econômicos e culturais. Contrapomos o diverso ao homogêneo, confrontamos o desigual com a equiparação, que é a aspiração básica da educação, pensada como capacitação para aumentar as possibilidades.

Assim nos questionamos: após algumas décadas de educação inclusiva no Brasil, ainda existe preconceito, ou estigma, com a pessoa com deficiência? Evidenciamos, ainda, o objetivo deste artigo de verificar, por meio das mídias audiovisuais, como as pessoas com deficiência são reconhecidas e visualizadas.

\section{Metodologia}

O método selecionado para a construção deste artigo é a netnografia, no qual a pesquisa é realizada em ambientes virtuais. Segundo Kozinets (2002 apud ROCHA; MONTARDO, 2005), a netnografia é definida como um método de pesquisa derivado da técnica etnográfica, desenvolvida no campo da antropologia. Este método é constantemente utilizado por pesquisadores das áreas da comunicação, do marketing, da antropologia e da sociologia.

Segundo Amaral, Natal e Viana (2008), essa vertente metodológica começou a ser explorada a partir do surgimento de comunidades virtuais, no final dos anos de 1980. No Brasil, entretanto, ainda são poucos os estudos voltados para essa questão, no que diz respeito à metodologia em si ou aos objetos analisados.

De acordo com Amaral, Natal e Viana (2008), a netnografia mantém as premissas básicas da tradição etnográfica levantadas a partir dos trabalhos de Geertz (2001): manter postura inicial de estranhamento do pesquisador em relação ao objeto; considerar a subjetividade; considerar os dados resultantes como interpretações de segunda e terceira mão; e, finalmente, considerar o relato etnográfico como de textualidades múltiplas.

Para Goetz e Lecompte (1988), etnografia é uma reconstrução analítica de cenários e grupos culturais que contempla as crenças, práticas, artefatos e conhecimentos compartilhados pela cultura que está sendo estudada, através de uma imersão profunda do pesquisador no grupo estudado. Geertz (1989) destaca que, mais do que uma descrição detalhada, a etnografia trata-se de uma interpretação do pesquisador do que seja o ponto de vista do observado, fundando a compreensão dos fenômenos sociais na busca por esse olhar do outro.

A compreensão da web como espaço de observação de comunidades que ali se estabelecem, segundo Hine (2005), pressupõe a constatação de que a internet é simultaneamente contexto cultural e artefato cultural. Neste mesmo sentido, Kozinets (2002 apud MONTARDO; CORDEIRO, 2009) propõe uma adaptação da etnografia para a netnografia, indicando as ressalvas e as oportunidades que devem ser observadas em razão de estar-se 
analisando grupos na web, predominantemente à distância.

Neste artigo, a netnografia é utilizada para a seleção da amostra via buscadores. Neste caso específico, realizamos a busca no YouTube. Foram encontrados 44.800 vídeos que envolvem a temática identidade e estigma da pessoa com deficiência.

\section{Resultados e Discussão: o estigma nos vídeos}

De acordo com a revista norte-americana Time, na edição de novembro de 2006, o YouTube é a melhor invenção do ano por, entre outros motivos, criar uma nova forma para milhões de pessoas se entreterem, se educarem e se chocarem de uma maneira como nunca foi vista (REVISTA..., 2006).

O YouTube é um site que permite que seus usuários carreguem, adicionem e compartilhem vídeos em formato digital. Assim, compreendemos que há uma rapidez em adicionar e remover vídeos das diversas intenções.

Selecionamos os vídeos aleatoriamente a partir dos descritores mais comuns utilizados: deficientes, deficiência visual, deficiência física, deficiência mental, deficiência intelectual, deficiência auditiva, pessoas com necessidades educacionais especiais, "mongoloide", débil mental, ceguinho, surdo (piada) e surdinho. Após a visualização dos vídeos, os agrupamos em eixos. O quantitativo dos vídeos localizados e seus eixos podem ser vistos na Tabela 1 a seguir.

Tabela 1 - Número de vídeos localizados e seus descritores

\begin{tabular}{l|c}
\hline Descritor & No de vídeos $^{\mathbf{0}}$ \\
\hline Deficientes e Pessoa com NEE & 16.650 \\
Deficiência visual e Ceguinho & 10.300 \\
Deficiência intelectual, Deficiência mental, Mongoloide e Débil Mental & 6.940 \\
Deficiência física & 5.880 \\
Deficiência auditiva, Surdo (piada) e Surdinho & 5.030 \\
\hline Total & $\mathbf{4 4 . 8 0 0}$ \\
\hline
\end{tabular}

Fonte: Elaborado pelas autoras deste artigo.

É possível verificar que, ao organizar os descritores afins, agrupando-os, evidenciou-se as categorias de análise. E, ainda, a maior incidência, quer dizer, o maior número de vídeos localizados foi de "deficientes e pessoa com NEE", seguido por "deficiência visual e ceguinho"; o menor número de vídeos localizados foi de "deficiência auditiva". Curiosamente, as categorias assim surgiram, ou emergiram, sendo todos da condição de deficiência, a saber: aqueles que têm impedimentos de longo prazo de natureza física, intelectual, mental ou sensorial, os quais, em interação com diversas barreiras, podem ter obstruída sua participação plena e efetiva na escola e na sociedade (BRASIL, 2008). Não foi evidenciado, nos vídeos, transtorno global do desenvolvimento nem superdotação/altas habilidades, lembrando que todos são público-alvo da educação especial.
De acordo com a Cartilha do Censo 2010 Pessoas com Deficiência (OLIVEIRA, 2012), 45.606.048 de brasileiros, $23,9 \%$ da população total, têm algum tipo de deficiência - visual, auditiva, motora e mental ou intelectual. A prevalência da deficiência variou de acordo com a natureza delas. A deficiência visual apresentou a maior ocorrência, afetando $18,6 \%$ da população brasileira. Em segundo lugar está a deficiência motora, ocorrendo em $7 \%$ da população, seguida da deficiência auditiva, presente em $5,10 \%$ dos brasileiros e da deficiência mental ou intelectual, em 1,40\%. Ao relacionar os dados fornecidos pela cartilha do censo com os vídeos aqui apresentados, visualizamos a correspondência entre eles.

A Cartilha do Censo 2010 - Pessoas com Deficiência (OLIVEIRA, 2012) descreve que a deficiência é um tema de direitos humanos e, como 
tal, obedece ao princípio de que todo ser humano tem o direito de desfrutar de todas as condições necessárias para o desenvolvimento de seus talentos e aspirações, sem ser submetido a qualquer tipo de discriminação.

\section{Deficientes e Pessoa com NEE}

Sobre a categoria "Deficientes e Pessoa com NEE", evidenciamos que é ultrapassada a escolha da nomenclatura e que, mesmo com os documentos oficiais atuais, ainda existem terminologias não oficiais e de cunho excludente como "deficiente". Muitos dos que optam por chamar o público-alvo da educação especial de "deficiência", no geral, chamam-no de "deficiente", e este último, no dicionário Aurélio (FERREIRA, 2014), consta como insuficiente, insatisfatório, medíocre.

E quanto ao termo "pessoas com necessidades educacionais especiais", utilizam porque se refere a todo o público da educação especial (deficiência, transtorno global do desenvolvimento e altas habilidades/superdotação), como descreve a Política Nacional de Educação Especial na Perspectiva da Educação Inclusiva (BRASIL, 2008), ou seria por uso aleatório?

O estigma é "definido como uma diferença indesejada, um atributo pejorativo que implica na intolerância do grupo" (MOREIRA, 2006, p. 2). O indivíduo que sofre pelo estigma passa a sentir-se inferiorizado e/ou limitado em relação aos demais de sua comunidade, ou de fora dela. De acordo com Fonseca (2001, p. 90), sua identidade é reduzida simplesmente ao seu "defeito", que "ofusca todas as outras dimensões de sua existência consideradas normais". A deficiência deve ser vista pela perspectiva dos direitos, dos direitos humanos. Não ascendemos aqui a proliferação de subculturas, de nichos fragmentados que possam buscar interesses afins. Deslumbramos uma sociedade tolerante, liberal e respeitosa, que nos permita viver intensamente dentro e fora da escola, em busca de vida digna com propósitos e sentidos.

Dhanda (2008) aponta que a Convenção da ONU - pela primeira vez na história das pessoas com deficiência, suas organizações representativas e outras instituições da sociedade civil - dispõe de um recurso jurídico para cobrar dos governos a aplicação dos direitos das pessoas com deficiência. Nesse sentido, a autora sugere que os defensores dos direitos humanos estendam analogicamente as lições da Convenção para outros setores dos direitos humanos, para além da deficiência.

\section{Deficiência Visual e ceguinho}

Destacamos que deficiência visual, segundo Nunes e Lomônaco (2008), é caracterizada pela impossibilidade de apreensão de informações do mundo pela visão. Existem dois tipos de deficiência visual: cegueira e baixa visão. As duas formas mais comuns de avaliação da capacidade visual são pela acuidade (discriminação de formas) e pelo campo visual (capacidade de percepção da amplitude dos estímulos). Cego é o indivíduo com acuidade menor que 0,1 ou campo visual com menos de 20 graus. Já a baixa visão é definida por uma acuidade de 6/60 e 18/60 e/ou um campo visual entre 20 e 50 graus. A capacidade visual é avaliada por essas medidas com todas as correções ópticas possíveis (óculos, lentes etc.). A perda da visão antes dos cinco anos de idade é chamada cegueira congênita. Já os cegos que perdem a visão a partir dessa idade são considerados cegos adventícios.

Nos vídeos aqui analisados, trata-se a deficiência visual de maneira generalizada, e, ao realizar a busca pelo descritor, logo aparecem os vídeos do humorista cego Geraldo Magela, em que ele se apresenta em tom de ironia e/ou satírico. Ele mesmo satiriza sua condição devido às perguntas insanas realizadas com frequência, por exemplo:

Pessoa - você é casado?

Magela - Sim.

Pessoa - Mas ela é normal? (Com admiração!)

Magela - Não. Ela tem antena, rodinha, entrada para DVD e já vem com MP3 acoplado.

Pessoa-Tem filhos?

Magela - Sim. Tenho dois. Cego não vê o que faz, devia ter 20 (risos).

Pessoa - São normais? (Pasmo)

Magela - Não. Tem um que voa.

Pessoa - Você é cego total? (Em tom duvidoso)

Magela - Não. Só até 6h. (YOUTUBE, 2008a). 
Seria essa a estratégia encontrada para lidar com a estigmatização e depreciação por sua condição de pessoa com deficiência visual? Assim nos mostra um dos vídeos (YOUTUBE, 2008a), e como este, há outros tantos do humorista em que apresentam o piadista e não a pessoa Geraldo. Há um vídeo em que, na entrevista a um programa noturno, por volta de $23 \mathrm{~h}$, em canal aberto, em mídia televisiva, logo no início, por incidente, derrama o copo com água que estava na mesa do entrevistador que, de imediato, pede que removam o copo antes que ele derrube tudo, em tom esdrúxulo.

Em outro vídeo (YOUTUBE, 2008b), ocorre uma entrevista com uma pessoa cega que diz existirem algumas pessoas que a aborrece, estigmatiza, mas diz não se importar. Será que cansou de lutar contra a hostilidade das pessoas que o rotularam? Acaso seria por haver tantos momentos estigmatizantes? Enquanto isso, visualizamos um vídeo sobre "Pegadinha": um dito cego usa sua bengala para levantar a saia das mulheres (YOUTUBE, 2016a). Esta é uma situação em que a pessoa forja possuir deficiência visual e se apresenta como alguém cínico e aproveitador. Em condição semelhante, há o vídeo intitulado "Dança do ceguinho" (YOUTUBE, 2008c), em que ressaltam a frase: “ $E u$ passo a mão também!'. Neste vídeo há novamente a apresentação da pessoa cega como aproveitadora.

Assim como o anterior, os vídeos "ceguinho no parque aquático" (YOUTUBE, 2010a) e "O ceguinho do 511-A” (YOUTUBE, 2008d), também estão em condições estigmatizadoras. Encontramos ainda um vídeo no qual os apresentadores fazem sucessivas piadas depreciativas e satirizam a condição de ser cego, e consideram isso um momento de descontração (YOUTUBE, 2016b). Realmente as pessoas consideram que a condição física, sensorial e/ou outra das pessoas com deficiência é motivo de diversão e entretenimento? Em outro vídeo (YOUTUBE, 2012a), o próprio cego, ou a pessoa que se utiliza da condição, informa que vai a uma boate em que a fila é muito grande e o mesmo quer fazer valer, com palavras dúbias, o direito assegurado na Lei $\mathrm{n}^{\circ} 10.048$ (BRASIL, 2000), que dá atendimento prioritário às pessoas portadoras de deficiência, aos idosos com idade igual ou superior a 60 anos, às gestantes, às lactantes, e às pessoas acompanhadas por criança de colo.

\section{Deficiência intelectual, Deficiência mental, Mongoloide e Débil Mental}

Deficiência intelectual, como hoje é chamada, tem uma relação direta com a história da Educação Especial no Brasil, e até hoje não apresenta instrumentos de anamnese conclusivos e $100 \%$ satisfatórios. Não é de fácil mensuração e depende da subjetividade de quem avalia clínica e pedagogicamente.

Os médicos foram os primeiros a estudar os casos de crianças com prejuízos mais graves e criaram instituições para crianças junto a sanatórios psiquiátricos. Este interesse dos médicos pelas pessoas com deficiências teria maior repercussão após a criação dos serviços de higiene mental e saúde pública, que, em alguns estados, deram origem aos serviços de inspeção médico-escolar e à preocupação com a identificação e educação dos estados anormais de inteligência.

O processo de popularização da escola primária pública se iniciou entre as décadas de 1920 e 1930 , quando o índice de analfabetismo no Brasil era de 80\% (MENDES, 2010). Neste período, a vertente psicopedagógica da educação de pessoas com deficiência no Brasil é influenciada pelas reformas nos sistemas educacionais de educação sob o ideário do movimento escolanovista, e é introduzido o uso dos testes de inteligência (escala de Binet-Simon) para identificar deficientes intelectuais. Com isso, observa-se uma maior preocupação no panorama nacional com a identificação dos casos leves de "anormalidade da inteligência" nas escolas regulares, uma vez que os casos mais graves eram rejeitados pela escola pública.

O desenvolvimento das escalas psicométricas é considerado um importante marco na história e no desenvolvimento da psicologia por diversos pesquisadores (ALMEIDA, 2002); no entanto, a maneira como foram empregadas na avaliação dos indivíduos com deficiência e a forma com que se popularizaram pode ter contribuído, de alguma maneira, para a construção de uma concepção de estagnação do desenvolvimento em detrimento da relação do sujeito com o ambiente (MAZZOTTA, 2001; VELTRONE, 2011), impregnando uma crença coletiva de que o desenvolvimento intelectual do deficiente evolui somente até uma 
determinada faixa etária, independentemente das relações que este indivíduo possa estabelecer em seu ambiente.

Helena Antipoff reúne certo número de professores, médicos, advogados, agrônomos, engenheiros e outros profissionais. Aponta-lhes a situação de abandono e miséria em que se encontra a infância desamparada que perambula pelas ruas da capital. Propõe-lhes a criação de uma sociedade de assistência, depois de sensibilizá-los quanto ao dever de acudir os necessitados, a Sociedade Pestalozzi (RAFANTE, 2006).

Descreve Rafante (2006, p. 95) que a Sociedade Pestalozzi era uma associação civil mantida por doações, inclusive do Estado, "destinada a proteger as crianças e adolescentes excepcionais e a preservar a sociedade e a raça, das influências nocivas para a sua saúde mental e equilíbrio moral".

A história ainda detém muitos meandros que aqui não nos cabe relatar, mas revela essa (des) construção do ser com deficiência intelectual, assim como as demais pessoas com deficiência.

Sobre Deficiência intelectual, Deficiência mental, Mongoloide e Débil Mental, encontramos 6.940 vídeos, os quais são chamados assim referindo-se à irresponsabilidade, ao fato de poderem fazer o que quiserem, com atitudes não pensadas e como se, por serem "deficientes", pudessem agir com atos descompromissados. No caso, nem todos possuem algum tipo de deficiência, na maioria são pessoas consideradas "normais" que se utilizam do imaginário estigmatizado de "mongoloide" como subterfúgio para atos e/ou comportamentos duvidosos frente à "normalidade ou moralidade" social.

No vídeo "As Pessoas mais Inteligentemente Burras da Terra" (YOUTUBE, 2012b), as atitudes são ridicularizadas, associadas à pouca inteligência, ao retardo. Em outro vídeo (YOUTUBE, 2010b), Janaína é chamada de mongoloide por se esquecer de fechar o ralo e não conseguir resolver a situação. Gera-se aqui a ideia de que não realizar atividades simples se deve à deficiência. É mais interessante estereotipar do que respeitar a condição da pessoa com deficiência? Pessoas que em nada se constituem com deficiência são chamadas de mongoloide, reforçando a ideia de que uma pessoa com deficiência é incapaz de realizar até uma atividade doméstica. Colocam em xeque a integridade e a condição emocional, social e física das pessoas que lutam para ter seus direitos reconhecidos e por espaços sociais dignos, que geram autonomia e cidadania. Este último é um vídeo típico de depreciação da pessoa com deficiência, assim como o vídeo intitulado como "Irmãos Mongoloides" (YOUTUBE, 2006), que é um desenho animado.

Nesses vídeos, alguns jovens se comparam a pessoas que apresentam dificuldades de raciocínio lógico, que apresentam incapacidade de realizar pequenas e simples atividades cotidianas. Atualmente, as pessoas com deficiência têm apresentado desempenho e condições superiores, que em nada os remete às condições apresentadas nestes vídeos, tampouco devem ser caracterizadas e/ou nomeadas como mongoloides. Pessoas ditas "normais" se apropriam destas terminologias para depreciar, as usam como xingamentos e em nenhum momento consideram a real situação das pessoas com deficiência, que historicamente se constitui como estigmatizada.

Os "cantores" que se apresentam em outro vídeo (YOUTUBE, 2011a), e autores do mesmo, utilizam a expressão mongoloide como adjetivo para a banda. Justificam a falta de profissionalismo, o comportamento e o poder expressar-se com seus amigos de maneira despretensiosa.

Com relação a débil mental, há um vídeo (YOUTUBE, 2011b) que apresenta um político depreciando um funcionário que, ao invés de chamá-lo de cidadão, chama-o de débil mental. Situação similar em outro vídeo (YOUTUBE, 2008e), no qual um deputado do PSDB, em 2008, pede reparação às pessoas com deficiência mental/débil mental pela maneira equivocada proferida pelo ex-governador do RJ, por ter equiparado débil mental a assassinos. A nosso ver, poderia gerar atos de violência contra as pessoas com deficiência. Evidenciamos ainda um vídeo (YOUTUBE, 2011c) em que o motorista do carro é comparado a um débil mental por sua falta de responsabilidade, imperícia e imprudência. Em geral, os vídeos que fazem referência a débil mental o equiparam a pessoas desequilibradas, imbecis, desatentas, agressivas, e, em geral, possuem uma linguagem não apropriada para representar as pessoas com e sem deficiência intelectual. 


\section{Deficiência física}

O Decreto no 3.298 (BRASIL, 1999), em seu art. $4^{\circ}$, considera:

Deficiência Física - alteração completa ou parcial de um ou mais segmentos do corpo humano, acarretando o comprometimento da função física, apresentando-se sob a forma de paraplegia, paraparesia, monoplegia, monoparesia, tetraplegia, tetraparesia, triplegia, triparesia, hemiplegia, hemiparesia, amputação ou ausência de membro, paralisia cerebral, membros com deformidade congênita ou adquirida, exceto as deformidades estéticas e as que não produzam dificuldades para o desempenho de funções.

O comprometimento da função física poderá acontecer quando existe a falta de um membro (amputação), sua má-formação ou deformação (alterações que acometem o sistema muscular e esquelético). Ainda encontraremos alterações funcionais motoras decorrentes de lesão do Sistema Nervoso e, nesses casos, observaremos principalmente a alteração do tônus muscular (hipertonia, hipotonia, atividades tônicas reflexas, movimentos involuntários e incoordenados) (BERSCH; MACHADO, 2007).

Após a apresentação acima da deficiência física, registramos um vídeo (YOUTUBE, 2015) que apresenta um show de piadas, no qual o humorista diz que o preconceito está na cabeça das pessoas, que o pai dele é deficiente físico e adora sair com ele porque não falta lugar para estacionar; e, ainda, enfatiza que é para o pai caprichar na "mancada" para as pessoas acreditarem (palavrão), e isso, a nosso ver, é de muito sarcasmo; como se viver com dificuldades motoras fosse mote de piadas ou entretenimento.

\section{Deficiência auditiva, Surdo e Surdinho}

De acordo com o Decreto $\mathrm{n}^{\circ} 5.626$ (BRASIL, 2005), considera-se pessoa surda aquela que, por ter perda auditiva, compreende e interage com o mundo por meio de experiências visuais, manifestando sua cultura principalmente pelo uso da Língua Brasileira de Sinais (Libras). E considera-se deficiência auditiva a perda bilateral, parcial ou total, de quarenta e um decibéis $(\mathrm{dB})$ ou mais, aferida por audiograma nas frequências de $500 \mathrm{~Hz}$, $1.000 \mathrm{~Hz}, 2.000 \mathrm{~Hz}$ e $3.000 \mathrm{~Hz}$.

Compreendida a definição de Surdez e deficiência auditiva, evidenciamos outro vídeo (YOUTU$\mathrm{BE}, 2010 \mathrm{c}$ ) que consideramos abusivo e que deveria ser envolvido em cunho punitivo por denegrir e referendar a abusividade à pessoa com deficiência. Ele mostra uma pessoa que diz ensinar como seduzir uma pessoa surda, mas o chama de mudinho. Muitos ainda mantêm em seu imaginário a ideia que todo surdo é mudo, o que não é verdade, pois há surdos oralizados. Daí, utiliza vocabulário vulgar e descreve como uma pessoa boba e carente, como se pode confirmar com o link, e ainda descreve que a vantagem é poder se beneficiar de seu veículo motorizado, de posse do bem material da pessoa aqui ridicularizada e exposta, a pessoa surda. A pessoa com deficiência tem sido instrumento de uso e abuso da pessoa sem deficiência, seja de uso/abuso físico, seja moral ou psicossocial. Cativam a pessoa surda, estabelecem relação de confiança, beneficiam-se de sua carência social e afetiva, estuprando, por fim, sua inocência e integridade.

Nos vídeos sobre pessoas surdas, faz-se referência à sexualidade, e, ainda por não entender a língua de sinais, os chamam de doido, louco. Além disso, a pessoa surda deixa de ser chamada por seu nome e é chamada pelos ouvintes de surdinho, eliminando sua condição identitária de pessoa com direitos e deveres, que deve ser respeitada pela pessoa que é, e não por sua especificidade aqui apresentada: ausência ou redução da audição. Inclusive, há produções que evidenciam surdez e AIDS e/ou outras doenças relacionadas ao sexo, como o trabalho de Bento e Bueno (2005), de Fernandes (2008) e Groce (2004), as quais enfatizam que as pessoas com deficiência, dentre elas os surdos, compõem a população de risco. Uma das possíveis causas são os poucos programas direcionados a esta população, que ainda são inferiores aos que se encontram disponíveis para a população em geral.

Resumindo o que foi encontrado nas categorias analisadas, a partir dos descritores apresentados na Tabela 1, destacamos que a pessoa com deficiência ainda é vista como: deficiente; irresponsável; desatenta; fora do padrão social; pessoa não inteligente; incapaz; dificuldade de raciocínio e lógica; agressiva; carente e frívolo. 
Como visto anteriormente, para Magalhães (2010) e Goffman (1980), a convivência não extingue o menosprezo e o preconceito das relações por si só. Estas expressões e/ou adjetivações são depreciativas e ainda utilizadas em meio social, divulgadas em mídia de ampla repercussão, conduzindo as pessoas com deficiência ao descrédito de forma descabida.

A sociedade considera e revalida, por motivo torpe, a exclusão, a depreciação, a inferiorização, fortalecendo um desequilíbrio social, mascarado, por vezes, por ações paliativas.

\section{Considerações Finais}

O presente artigo objetivou verificar, por meio das mídias audiovisuais, como as pessoas com deficiência são reconhecidas e, com isso, buscar responder se, com algumas décadas de educação inclusiva no Brasil, ainda existe preconceito e/ ou estigma sobre a personificação da pessoa com deficiência.

Por meio da netnografia, identificamos algumas características e/ou representações e sentidos sobre a pessoa com deficiência que sabemos que são ainda remanescentes de um longo período de exclusão, uma via marginal de estigmatização que deixou marcas e resíduos no público diretamente atingido, seja pelas ausências políticas, seja pela colonização social das mentes daqueles que não veem nas pessoas com deficiência um perfil digno de semelhança. Ressalta-se que a interpretação dada pelas pesquisadoras foi realizada a partir do olhar do outro nos vídeos e resguardada as limitações da distância e outras particularidades do método.

A pessoa com deficiência, embora possua alguma especificidade visual, auditiva, física e intelectual, e, em muitos casos, não aceite a postulação médica - deficiente -, não quer ser vista pela deficiência, qualquer que seja, mas pela sua diversidade, sendo respeitada por suas diferenças, por sua singularidade. A pessoa com deficiência não deve ser negada, nem se deve tampouco fixar-se apenas nas deficiências, não se deve prover um conceito de deficiência que a reduza às lesões e aos impedimentos físicos e/ou sensoriais; ao contrário, é possível e viável que se pense nas suas possibilidades e potencialidades, para além de qualquer (im)possível e marginal limitação.

Sobre a deficiência, é preciso desconstruir a ideia de castigo ou punição por atos indevidos de seus pais e familiares. Não deve mais ser vista como doença nem é necessário a busca de uma cura em prol da aceitação social. Não deve ser vista também como merecedora de caridade e assistencialismo. Evidenciamos ainda que não queremos um olhar de plena complacência, a ponto de subjugar à incapacidade.

Sobre o preconceito, consideramos ser não apenas a ausência de igualdade pelo olhar daquele que se considera perfeito e superior, mas também uma arma covarde de eliminação, de exclusão, de humor negro sobre a situação das pessoas com deficiência, aqui apresentadas como entretenimento, dentre outros; que utilizam com o fim da opressão, da subserviência, da humilhação etc. Enquanto isso, evidenciamos que a pessoa com deficiência é vítima dessa dominação preconceituosa, sendo capaz de ser privada de sua conquista diária e até mesmo sendo extirpada de si e do meio social.

Sobre as ações discriminatórias, ressaltamos que, em primazia, haveríamos de reconhecer a potencialidade das pessoas com deficiência sem julgamentos prévios e sem a necessidade de visualizá-la como não igual. Ainda o elemento virótico, epidêmico e que enclausura, aqui considerado preconceito/estigma, deveria ser argumento feroz para a eliminação das barreiras e de promoção à justiça com medidas cabíveis e imediatas.

\section{REFERÊNCIAS}

ALMEIDA, Leandro S. As aptidões na definição e avaliação da inteligência: o concurso da análise fatorial. Paidéia, Ribeirão Preto, SP, v. 12, n. 23, p. 5-17, 2002.

AMARAL, Ligia Assumpção. Espelho convexo: o corpo desviante no imaginário coletivo, pela voz da literatura infanto-juvenil. 1992. 441f. Tese (Doutorado em Psicologia) - Universidade de São Paulo, São Paulo, 1992. 
AMARAL, Adriana; NATAL, Geórgia; VIANA, Lucina. Netnografia como aporte metodológico da pesquisa em comunicação digital. 2008. Comunicação cibernética. Disponível em: <http://revistaseletronicas.pucrs.br/ojs/ index.php/famecos/article/viewFile/4829/3687.AcessadoAcesso>. Acesso em: 22 jan. 2013.

ARAN, Artur P. Introdução. In: ALCUDIA, Rosa. Atenção à diversidade. Porto Alegre: Artmed, 2002. p. 11-12.

BERSCH, Rita; MACHADO, Rosângela. Conhecendo o aluno com deficiência física. In: SCHIRMER, Carolina. Et al (Org.). Atendimento educacional especializado - deficiência física. Brasília, DF: SEESP/SEED/MEC, 2007. p. 15-26.

BENTO, Isabel C. B.; BUENO, Sônia M. V. A Aids sob a ótica do surdo adulto jovem. Jornal de Doenças Sexualmente Transmissíveis, v. 17, n. 14, p. 288-294, 2005. Disponível em: <http://www.dst.uff.br//revista17-4-2005/A-Aids-Sob-a-Etica.pdf>. Acesso em: 04 fev. 2014.

BRASIL. Presidência da República. Casa Civil. Decreto no 3.298, de 20 de dezembro de 1999. Dispõe sobre a Política Nacional para a Integração da Pessoa Portadora de Deficiência, consolida as normas de proteção, e dá outras providências. Brasília, DF, 1999. Disponível em: <http://www.planalto.gov.br/ccivil_03/decreto/d3298.htm>. Acesso em: 04 fev. 2014.

Presidência da República. Casa Civil. Lei no 10.048, de 08 de novembro de 2000. Dá prioridade de atendimento às pessoas que especifica, e dá outras providências. Brasília, DF, 2000. Disponível em: $<\mathrm{http}: / /$ www.planalto. gov.br/ccivil_03/leis/110048.htm>. Acesso em: 12 dez. 2012.

. Presidência da República. Casa Civil. Decreto n 5.626, de 22 de dezembro de 2005. Regulamenta a Lei no 10.436, de 24 de abril de 2002, que dispõe sobre a Língua Brasileira de Sinais - Libras, e o art. 18 da Lei no 10.098, de 19 de dezembro de 2000. Brasília, DF, 2005. Disponível em: <http://www.planalto.gov.br/ccivil_03/_ato20042006/2005/decreto/d5626.htm>. Acesso em: 12 jan. 2014.

Ministério da Educação. Política Nacional de Educação Especial na Perspectiva da Educação Inclusiva. Brasília, DF: MEC, 2008. Disponível em: <http://portal.mec.gov.br/index.php?option=com docman\&view=download\&alias $=16690$-politica-nacional-de-educacao-especial-na-perspectiva-da-educacao-inclusiva-05122014\&Itemid=30192>. Acesso em: 12 abr. 2010.

Presidência da República. Casa Civil. Decreto no 6.949, de 25 de agosto de 2009. Promulga a Convenção Internacional sobre os Direitos das Pessoas com Deficiência. Brasília, DF, 2009. Disponível em: <http://www. planalto.gov.br/ccivil_03/_ato2007-2010/2009/decreto/d6949.htm>. Acesso em: 18 fev. 2013.

Presidência da República. Casa Civil. Lei no 13.146, de 06 de julho de 2015. Institui a Lei Brasileira de Inclusão da Pessoa com Deficiência (Estatuto da Pessoa com Deficiência). Brasília, DF, 2015. Disponível em: $<$ http://www.planalto.gov.br/ccivil_03/_ato2015-2018/2015/lei/113146.htm>. Acesso em: 06 dez. 2017.

DHANDA, Amita. Construindo um novo léxico dos direitos humanos: Convenção sobre os Direitos das Pessoas com Deficiências. SUR - Revista Internacional de Direitos Humanos, São Paulo, v. 5, n. 8, p. 43-59, jun. 2008. Disponível em: <http://www.scielo.br/scielo.php?pid=S1806-64452008000100003\&script=sci_arttext $>$. Acesso em: 01 abr. 2013.

FERNANDES, Ana Paula Cunha dos Santos. A escolarização da pessoa com deficiência nas comunidades ribeirinhas da Amazônia Paraense. 2015. 280f. Tese (Doutorado em Educação Especial) - Programa de Pós-Graduação em Educação Especial, Universidade Federal de São Carlos, São Paulo, 2015.

FERNANDES, Janaína Francisca Pinto. Doenças sexualmente transmissíveis: análise psicossocial das representações de alunos surdos. 2008. 172f. Dissertação (Mestrado em Enfermagem) - Faculdade de Farmácia, Odontologia e Enfermagem da Universidade Federal do Ceará, Fortaleza, 2008.

FERREIRA, Aurélio Buarque de Holanda. Dicionário Aurélio de Português Online. Deficiente. Disponível em: $<$ http://www.dicionariodoaurelio.com/Deficiente.html>. Acesso em: 26 mar. 2014.

FONSECA, Eduardo P. Aquino. Faces da identidade afro-brasileira: um estudo do estigma e preconceito religiosos. Cadernos de Estudos Sociais, Recife, v. 17, n. 1, p. 87-108, jan./jun. 2001.

GEERTZ, Clifford. Nova luz sobre a antropologia. Rio de Janeiro: Zahar, 2001.

A interpretação das culturas. Rio de Janeiro: Guanabara, 1989.

GOETZ, J. P.; LECOMPTE, M. Etnografia y diseño cualitativo en investigación educativa. Madri: Morata, 1988. 
GOFFMAN, Erving. Estigma: notas sobre a manipulação da identidade deteriorada. 3. ed. Rio de Janeiro: Zahar, 1980.

GROCE, Norah. Levantamento mundial sobre HIV/AIDS e deficiências. 2004. Disponível em: <http://siteresources.worldbank.org/EXTLACREGTOPHIVAIDS/Resources/LevantamentoMundialSobreHIVAidseDeficincias_NoraGroce_Port.doc>.Acesso em: 04 fev. 2014.

HINE, Christine. Virtual methods: issues in social research on the internet. Oxford: Berg, 2005.

MAGALHÃES, Rita C. B. P. A pessoa com deficiência e a crise das identidades na contemporaneidade. Cadernos de Pesquisa, v. 40, n. 139, p. 45-61, jan./abr. 2010.

MAZZOTTA, M. J. S. Educação Especial no Brasil: história e políticas públicas. 3. ed. São Paulo: Cortez, 2001.

MENDES, Enicéia. Breve histórico da Educação Especial no Brasil. Revista Educación y Pedagogía, v. 22, n. 57, p. 93-109, maio/ago. 2010. Disponível em: <http://aprendeenlinea.udea.edu.co/revistas/index.php/revistaeyp/ article/viewFile/9842/9041>. Acesso em: 12 mar. 2012.

MONTARDO, Sandra Portella; CORDEIRO, Bruna Chilanti. Estigma em blogs de pessoas com deficiência auditiva. Revista da Associação Nacional dos Programas de Pós-Graduação em Comunicação - E-compós, Brasília, DF, v. 12, n. 1, p. 1-15, jan./abr. 2009.

MOREIRA, Virgínia. Estigma: "Minha doença é invisível". In: CONGRESSO INTERNACIONAL DE PSICOPATOLOGIA FUNDAMENTAL, 2., 2006, Belém. Anais eletrônicos... Belém: UFPA, 2006. Disponível em: <http:// www.psicopatologiafundamental.org/pagina-trabalhos-completos-465>. Acesso em: 06 dez. 2017.

NUNES, Sylvia da Silveira; LOMÔNACO, José Fernando Bitencourt. Desenvolvimento de conceitos em cegos congênitos: caminhos de aquisição do conhecimento. Revista Semestral da Associação Brasileira de Psicologia Escolar e Educacional (ABRAPEE), v. 12, n. 1, p. 119-138, jan./jun. 2008.

OLIVEIRA, Ivanilde Apoluceno. História, arte, educação: a importância da arte na educação inclusiva. In: BAPTISTA, C.; CAIADO, Katia Regina Moreno; JESUS, Denise Meyrelles de. Educação especial: diálogos e pluralidade. Porto Alegre: Mediação, 2008. p. 255-266.

OLIVEIRA, Luiza Maria Borges. Cartilha do Censo 2010 - Pessoas com Deficiência. Secretaria de Direitos Humanos da Presidência da República (SDH/PR) / Secretaria Nacional de Promoção dos Direitos da Pessoa com Deficiência (SNPD) / Coordenação-Geral do Sistema de Informações sobre a Pessoa com Deficiência; Brasília, DF: SDH/PR / SNPD, 2012.

OMOTE, Sadao. Estigma no tempo da inclusão. Revista Brasileira de Educação Especial, Marília, SP, v. 10, n. 3, p. 287-308, 2004.

RAFANTE, Heulália Charalo. Helena Antipoff e o ensino na capital mineira: a Fazenda do Rosário e a educação pelo trabalho dos meninos "excepcionais" de 1940 a 1948. 2006. 247p. Dissertação (Mestrado em Educação) Programa de Pós-Graduação em Educação da Universidade Federal de São Carlos, São Carlos, SP, 2006.

REVISTA “Time” elege YouTube a melhor invenção do ano. Globo.com, Rio de Janeiro, 07 nov. 2006. Disponível em: <http://g1.globo.com/Noticias/Tecnologia/0,,AA1340903-6174-363,00.html>. Acesso em: 08 dez. 2017.

ROCHA, Paula Jung; MONTARDO, Sandra Portella. Netnografia: incursões metodológicas na cibercultura. Compós - Revista da Associação Nacional dos Programas de Pós-Graduação em Comunicação, p. 5-22, dez. 2005. Disponível em: <http://www.compos.org.br/seer/index.php/e-compos/article/viewFile/55/55>. Acesso em: 19 dez. 2012.

SCHILLING, Flávia; MIYASHIRO, Sandra Galdino. Como incluir? O debate sobre o preconceito e o estigma na atualidade. Educação e Pesquisa, São Paulo, v. 34, n. 2, p. 243-254, maio/ago. 2008.

VELTRONE, Aline. Inclusão escolar do aluno com deficiência intelectual no Estado de São Paulo: identificação e caracterização. 2011. 192f. Tese (Doutorado em Educação Especial) - Centro de Educação e Ciências Humanas. Programa de Pós-Graduação em Educação Especial da Universidade Federal de São Carlos, São Carlos, SP, 2011.

YOUTUBE. Irmãos Mongoloides - desenho animado. 2006. Disponível em: <https://www.youtube.com/ watch?v=1F76o2k2Hb4>. Acesso em: ago. 2016.

Geraldo Magela ceguinho e as perguntas engraçadas. 2008a. Disponível em: $<$ https://www.youtube.com/ 
watch?v=OI4pQ04MBmc >. Acesso em: ago. 2016.

. Entrevista - ceguinho da Hecílio. 2008b. Disponível em: <https://www.youtube.com/ watch? $=$ BG42HRVcNHw>. Acesso em: ago. 2016.

. Dança do ceguinho - Mc Ceguilha. 2008c. Disponível em: <https://www.youtube.com/ watch? $=$ YpYC1IGyLM8>. Acesso em: ago. 2016.

. O Ceguinho do 511-A. 2008d. Disponível em: $<$ https://www.youtube.com/watch?v=JidPK45cPXU>.

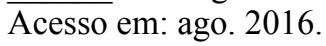

. Otavio Leite critica o termo "débil mental". 2008e. Disponível em: $<$ https://www.youtube.com/watch?v= eAyv8Apklw>. Acesso em: ago. 2016.

. Ceguinho no Parque Aquático. 2010a. Disponível em: $<$ https://www.youtube.com/watch?v=nBXfZ36J718>. Acesso em: ago. 2016.

Janaína é chamada de mongoloide por Melancia. 2010b. Disponível em: $<$ https://www.youtube.com/ $\overline{\text { watch? }} \mathrm{v}=\mathrm{BwQaCNJPNyc}>$. Acesso em: ago. 2016.

. Como seduzir um mudinho ou surdinho - deficiente auditivo. 2010c. Disponível em: $<$ https://www.youtube. com/watch? $\mathrm{v}=$ oaqw91OJr-E $>$. Acesso em: ago. 2016.

. Oração. A banda mais mongoloide da cidade. 2011a. Disponível em: <https://www.youtube.com/ watch? $v=$ b_mzrvNNeTY>. Acesso em: ago. 2016.

. O débil mental de Campo Magro. 2011b. Disponível em: <https://www.youtube.com/watch?v=5AiJZlmYxF8>. Acesso em: ago. 2016.

. Acidente-Débil Mental é pouco. 2011c. Disponível em: $<$ https://www.youtube.com/watch?v=Hr2ih2Rdkb8>. Acesso em: ago. 2016.

. Protesto do Ceguinho na Toca da Gamba “uma casa de respeito...”. 2012a. Disponível em: $<$ https://www. youtube.com/watch?v=Vjh2mQNst_I $>$. Acesso em: ago. 2016.

. Mundo Canibal - As pessoas mais inteligentemente burras da Terra. 2012b. Disponível em: $<$ https://www. youtube.com/watch?v=hylujVFJs-M>. Acesso em: ago. 2016.

Comédia standup, cinema, vida de pai, deficientes físicos. 2015. Disponível em: <https://www.youtube. com/watch?v=ugDa1aQ7Fus>. Acesso em: ago. 2016.

. Ceguinho no Shopping - Caio responde \#60. 2016a. Disponível em: $<$ https://www.youtube.com/ $\overline{\text { watch? }}=$ DZn2Q_uFL7Q>. Acesso em: ago. 2016.

. WebBullying (Facebullying) \#114 - Jefinho, o Cego. 2016b. Disponível em: <https://www.youtube.com/ watch? $\mathrm{v}=\mathrm{Yc} 97 \mathrm{jX}-\mathrm{xFOY}>$. Acesso em: ago. 2016.

Recebido: 22/05/2017

Aprovado: 19/11/2017 